\title{
El espacio simbólico: la Santa Cruz de los Milagros de Querétaro
}

\section{The Symbolic Space: the Holy Cross of the Miracles of Querétaro}

EnRIQUe Brito Miranda [jose.enrique.brito@uaq.mx]

Universidad Autónoma de Querétaro, México

\section{RESUMEN}

El presente trabajo es fruto de la exploración del discurso de cuatro crónicas religiosas franciscanas del siglo XVIII en torno a la construcción y simbolización de un espacio religioso y textual capaz de marcar el referente fundacional de una institución franciscana y de la crónica de Propaganda Fide de la Nueva España. Los cronistas estudiados son: el escritor zacatecano fray José de Castro, del castellano fray José Díez, el queretano fray Isidro Félix de Espinosa y el toluquense fray Juan Domingo Arricivita.

\section{Palabras Clave}

Espacio simbólico; crónica; metáfora; alegoría; hipérbole; evangelización y salvación

\begin{abstract}
This work is the result of the exploration of the discourse of four Franciscan religious chronicles of the eighteenth century around the construction and symbolization of a religious and textual space capable of marking the founding reference of a Franciscan institution and the chronicle of Propaganda Fide in the New Spain. The chroniclers studied include: the Zacatecan writer Fray José de Castro, the Castilian Fray José Díez, the Queretano Fray Isidro Félix de Espinosa and the Tolucan Fray Juan Domingo Arricivita.
\end{abstract}

\section{KEYWORDS}

Symbolic space; chronicle; metaphor; allegory; hyperbole; evangelization and salvation

RECIBIDO 2018-04-29; ACEPTADO 2018-06-17 
La Orden de Frailes Menores, mejor conocida como la orden franciscana, tiene una larga tradición de documentar, sistematizar y reflexionar en torno a su labor misional; probablemente el género más recurrido para indagar y constatar su trabajo de predicación evangélica ha sido el de la crónica religiosa. En términos generales, estas crónicas presentan la contribución de la Orden en la Historia de la Salvación; es decir, en el caso de los franciscanos sería la memoria de la manera en que la Orden ayudó a la Iglesia para la reformación de fieles o conversión de paganos y su incorporación a la Iglesia. Ahora bien, desde el punto de vista formal, las crónicas religiosas franciscanas se presentan fragmentadas e inconclusas, por la sencilla razón de que otorgan a Dios la facultad de ser el único que puede concluir la Historia, pues esa es una atribución divina y no del hombre. En este sentido, los textos entendidos por los cronistas como la descripción de uno de tantos segmentos del peregrinar humano en la Historia de la Salvación, quedan abiertos, con la finalidad de enfatizar la idea de que solo Cristo engloba al tiempo, es el alfa y omega de la Historia. Por otra parte también este carácter inconcluso del relato tiene el objetivo de permitir que el siguiente cronista, en su papel de narrador testigo y partícipe de la historia de la Salvación, continúe con la narración de los hechos.

Otro elemento constitutivo de las crónicas franciscanas es el de presentar la vida de los religiosos que se destacaron por su testimonio firme de fe y de vida virtuosa, en concordancia con las virtudes teologales y cardinales que propone la Iglesia y, como religioso franciscano, los modelos deseables de fraile seguidor de Francisco de Asís.

La crónica franciscana en la Nueva España es heredera de la europea; retoma la forma de presentación temática en orden cronológico y la exposición de retratos hagiográficos arrancan a partir del primer fallecimiento o "tránsito" del santo varón de la Provincia franciscana. Es importante mencionar que las crónicas franciscanas en el Nuevo Mundo no reducen su contenido a un recuento biográfico sino que están enriquecidas por la reflexión de su experiencia misional, por lo general combina en un discurso la descripción geográfica, la historiografía y la antropología de los pueblos que conforman las provincias. Esta manera de presentar el discurso induce al lector a visualizar la contribución de la provincia franciscana en la Historia de la Salvación, en la cimentación de la Iglesia novohispana, en la edificación de su grupo misional y en la construcción de una sociedad cristiana en pueblos con una rica tradición cultural pagana. Si se observan las crónicas de fray Gerónimo de Mendieta Historia Eclesiástica Indiana y la de fray Juan de Torquemada Monarquía Indiana se puede constatar que la disposición de los temas, en el nivel de la estructura, permite al lector introducirse en un mundo extraño que se despliega mediante descripciones de la historia y la cultura de los pueblos; así, en los primeros libros de cada obra respectivamente, se abordan la historia natural y moral de los pueblos, después se desarrollan relatos historiográficos sobre las formas y condiciones de la evangelización y, por último, los retratos hagiográficos de los destacados religiosos de la provincia.

Además de las crónicas provinciales están las de los colegios Propaganda Fide; éstas no presentan la información para testimoniar la activad de las provincias sino de los colegios apostólicos de Propaganda Fide fundados a partir del siglo XVII. Al igual que las provinciales, las de Propaganda Fide documentan la participación de los colegios de misioneros en la Historia de la Salvación bajo una estructura tripartita, sin embargo las variaciones son temáticas: en lugar de abordar la historia y cultura de los pueblos de la demarcación provincia, así como su fundación, se presentan en las de Propaganda Fide la historia y los antecedentes de la fundación de 
los colegios. La segunda parte versará sobre las misiones populares y las de infieles y la tercera está conformada por retratos hagiográficos de los religiosos de los colegios que destacaron por la santidad de vida y el esfuerzo, desprendimiento y eficacia en su trabajo misional.

Las primeras crónicas de la Nueva España se escribieron durante los primeros años del siglo XVIII y dan cuenta de la fundación de colegios como el de la Santa Cruz de Querétaro, el de Zacatecas y el de Guatemala así como el área de influencia que cada institución tuvo respectivamente en los extensos territorios de norte de la Nueva España como Coahuila, Texas, Nuevo México, Sonora, Arizona y Alta California o los del sur,en los impenetrables lugares selváticos de la Lacandonia mexicana y guatemalteca y de la Talamanca costarricense.

Ahora bien, en las tres primeras crónicas aparece la preocupación de los autores por dejar sentada la autoridad y primacía del Colegio de Propaganda Fide de la Santa Cruz de Querétaro como primera institución de este tipo en Hispanoamérica. Para llevar a cabo este cometido desplegarán estrategias discursivas encaminadas a trasformar el espacio del Colegio de la Santa Cruz en un lugar simbólico que diera cuenta al mismo tiempo la conversión de los naturales, la fundación del pueblo de Querétaro, la historia de la devoción y culto de la Cruz de Piedra y el establecimiento del primer colegio de misioneros en la Nueva España.

Para entender cómo se lleva a cabo este proceso en el discurso de las crónicas es pertinente aclarar de manera general algunas características de los espacios sagrados. La transformación de un espacio común y corriente en uno sagrado implica un cambio en la función sensorial de dicho lugar; primero mediante la conciencia de separación entre espacio sagrado y profano: el sagrado debe enfatizar ciertos aspectos sensibles que permitan establecer una singularidad misteriosa donde se manifieste una presencia, un poder, una fuerza que, a decir de Mircea Eliade, sobrepase la experiencia natural de hombre, mediante manifestaciones de poder totalmente distinto de las fuerzas naturales pero tomados del mundo natural y que despierten el visitante ciertas vivencias irracionales de certeza y armonía. En otras palabras nos dice que el espacio sagrado es un lugar saturado de ser, de potencia, de perennidad, de eficacia y de sentido. Un lugar de misterio caracterizado por elementos racionales e irracionales, diáfanos y nebulosos (Eliade 2010: 148).

Además de los templos, los franciscanos en Querétaro se abocaron a la sacralización de un espacio abierto que contenía una cruz de madera que habían levantado en los primeros años de la evangelización. Con los años esta cruz fue sustituida por una de piedra y su entorno se transformó cuando se enriqueció con elementos arquitectónicos hechos para dar realce a la Cruz. De manera paralela, en el discurso escrito de las crónicas provinciales y de las de Propaganda Fide se construyó la narrativa del origen y desarrollo del culto de la Santa Cruz de los Milagros de Querétaro mediante el montaje de un espacio simbólico.

Las primeras menciones aparecen en pequeños relatos de la Crónica de Michoacán de fray Alonso de la Rea en 1639, bajo la temática de la devoción y el culto de la Santa Cruz de Querétaro; posteriormente, una vez establecido el Colegio de Propaganda Fide en 1683, los relatos y descripciones que aparecen en las crónicas serán más abundantes, con variedad de matices temáticos y con un claro sentido de exaltar la relación entre el culto popular a la Cruz de Piedra y la fundación Providencial del Colegio de misioneros apostólicos de Propaganda Fide como puede verse en las obras de José Díez de 1702, de José de Castro, de 1711 y de fray Isidro Félix de Espinosa de 1746. 
Los indicios que presenta fray Alonso de la Rea en la construcción de la simbolización del espacio de la entonces ermita de la Cruz de los Milagros se presentan bajo el siguiente orden: primero establece una brevísima descripción geográfica de la ermita y del pueblo de Querétaro; después el relato historiográfico de la evangelización de la región de Querétaro llevada a cabo a diez años de la caída de la ciudad de México Tenochtitlán por las tropas de Hernán Cortés, en este punto, el cronista destaca la temprana presencia franciscana y el papel protagónico de la Orden en estos territorios que servirían de umbral para la conquista y evangelización del norte de la Nueva España; posteriormente fray Alonso sube un escalón cualitativo al presentar a la Cruz como símbolo de la cristianización de los naturales de estas tierras a través de la descripción y reflexión de una representación pictórica ubicada en el zócalo de la Cruz en la que aparecían unos indios cortándose el cabello y otros ya con el pelo corto como prueba de su disposición para adoptar la fe católica. Cabe destacar que esta pintura aún estaba a mediados del siglo XVII en el pedestal de la cruz.

Además de este elemento simbólico aparecen también los primeros testimonios escritos sobre los milagros de la Cruz; el cronista de la Provincia de San Pedro y San Pablo de Michoacán presenta pequeños relatos piadosos y testimoniales sobre la devoción y el culto a la Cruz (Rea 1996: 193). Aquí ya aparecen las primeras narraciones sobre los favores milagrosos de la Cruz por lo que se puede inferir que es en este siglo cuando la Cruz pasa de ser un símbolo exclusivo de la evangelización de los indios naturales de esta tierra a un símbolo milagroso que no distinguía a poblaciones por su casta. Años más tarde, los cronistas de Propaganda Fide intensificarán este simbolismo al enfatizar, mediante hipérboles e interpretaciones providencialistas, la relación entre los beneficios recibidos por la Cruz para la reciente cristianización de los indios y los favores con los que se beneficiaba la población y, principalmente por el hecho providencia de que el nuevo instituto había sido fundado en el espacio que resguardaba a la famosa Cruz. Por todas estas características la imagen de la Cruz se convertirá durante el siglo XVIII en el emblema no sólo de los misioneros de Propaganda Fide.

Ahora bien, si se observa la disposición de cada crónica y se siguen sus respectivos hilos discursivos se constatarála evolución de la percepción de la Cruz; al evolucionar desde su creación como símbolo de la evangelización de los pobladores originarios y continuar como símbolo piadoso, milagroso y protector de toda la población de Querétaro para convertirse luego en el símbolo del hecho providencial de que el colegio de misioneros estuviera fundado en ese lugar y fuera el acicate de los misioneros de este instituto para la evangelización del sur y norte de la Nueva España.

El primer cronista del Colegio de Propaganda Fide de la Nueva España fray José de Castro aborda el tema de la fundación de este instituto inicia con una breve explicación sobre el tipo de fuentes disponibles; el caso que a continuación se presenta está basado en un testimonio indígena:

Llamavase este gobernador don Balthasar Martin, i aviendo dicho que era su declaración entre los indios casiques mui común, llamó el Padre Obispo otro indio casique principal llamado don Diego, i preguntando de la mesma forma dijo puntualmente lo mesmo que el Gobernador avía testificado añadieron ambos que dicho Venerable Padre puso allí la Cruz porque servía de iglesia en donde otros compañeros religiosos baptisaba i instruía en el mesmo lugar a los indios chichimecos que 
convertía y formó de carrizos, y paja una capilla, y dos casillas pajisas; una que servía de convento i otra de hospital para curar a los indios, i enfermos i mostraron los cimientos que casi duraba el dicho año de 50 que eran unas piedras puestas en forma en que se sustentaban los maderos de las casillas pobres i de la hermita i lo que dicen que callaron los ministros manifestaron las piedras. Juraron también los indios i muchos testigos españoles aver sido en el lugar de la Santa Cruz la primer iglesia de Querétaro, en que se celebraron missas y se administraron sacramentos, i que en la peana estaban pintados los religiosos baptisando indios chichimecos i cortándoles los cabellos, las quales pinturas duraron allí mucho tiempo, i fueron vistas de todos los vecinos que vivían, no sólo en el tiempo de la conquista sino muchos años después de la fundación i pacificación de Querétaro i siendo las pinturas antiguas, según Platón: testigos callados i verdaderos, acreditan estas pinturas que los testigos españoles e indios depusieron. (Castro 1711: 11)

Para ascender al nivel simbólico del texto el cronista presenta la información a manera de contrapunto; por una parte expone la versión india mediante una forma pictórica y un testimonio oral. En la pictórica aparece una pintura en el zócalo de la cruz con una representación de los indios aceptando el cristianismo bajo las formas de representación mesoamericana de plasmar dos cuadros: el primero con unos indios con el cabello largo, el segundo los religiosos cortando el pelo a los indios; por otra parte el testimonio oral se refiere a la pintura como elemento de aceptación a la vez que presenta los primeros años del cristianismo en Querétaro actuando con los franciscanos como predicadores y administradores de los sacramentos. El segundo elemento del contrapunto está formado por la dupla versión española escrita y sentencia de Platón: en la primera deja ver que probablemente es más fiel la versión sencilla de los naturales, ya que captan de manera directa e intuitiva la profundidad de la Cruz y enfatiza este componente con la sentencia. Finalmente el elemento integrador del contrapunto es la Cruz, elemento misterioso capaz de abrazar y cobijar las dos versiones.

El siguiente escalón en la construcción simbólica lo configura Castro mediante la presentación de elementos intertextuales, como el relato bíblico del sueño de Nabucodonosor mencionado en el Libro de Daniel, (Dan. 2, 26-45) en donde aparece una gran estatua de brillo extraordinario, para después mostrarnos la Cruz de Querétaro, como un símbolo magnificente que todo lo domina; para resaltar la importancia de este monumento cristiano, la contrasta con la estatua que vio el antiguo rey caldeo y utiliza la antítesis, a la manera típica de una pieza oratoria, que además de ser didáctica también ofrece un sentido de distinción y grandeza:

Aquella piedra que cayó de el monte sin que fuera necesario que hubiera manos para impelerla i puso en tierra la soberbia estatua de Nabuco me parece que fue un misterioso retrato de nuestra Cruz de Piedra Milagrosa, aquella fue piedra de monte, i esta tiene su situación en un montecillo, que está en la parte oriental de Querétaro; aquella derribó una estatua, i esta ha derrocado las vanas estatuas de los ídolos, que los ciegos indios adoraban. Aquella creció a ser grande en el monte i la nuestra creció, i aún en este tiempo crece, que es una de las maravillas de esta reliquia, no en la quantidad sino en el culto. (Castro 1711: 13)

Más adelante retoma el testimonio de los indios pero ahora ya como imagen ya interpretada del pasado: 
Grande milagro es de nuestra Cruz moverse, i no menos milagro el aver movido a los bárbaros indios chichimecos a dejar sus idolatrías, ussos y costumbres i dejarse cortar al pie de la Cruz los cabellos, en que tienen toda su gala. Podemos llamar a esta maravillosa reliquia la conquistadora de estas tierras de Querétaro... (Castro 1711:17)

La cuestión de lo milagroso se incorpora como uno de los temas centrales y abrirá toda una forma de relatos que describen y narran los prodigios de una Cruz que tiembla y que crece.

Algunos relatos mezclan lo verdadero y lo verosímil mediante anclajes temporales y espaciales: el de tiempo ubicado en el año de 1609 y el espacio mediante la localización de una capilla anterior al actual templo; además el hecho se realiza con un personaje con nombre y apellido, miembro de la Orden de Frailes Menores y de los que hay registros; la narración se centra más en el efecto subjetivo del milagro efectuado y no en los medios de constatación del mismo, lo que provoca que el lector se contagie de la conmoción de su narrador:

El año de 1609, día de la invención de la Sanctíssima Cruz cantando la missa en la pobre capilla un religi[o]so francisco llamado fray José de Valderrában, comenzó a vista de todo el concurso a moverse la Cruz Sanctíssima con maior movimiento, que suelen los árboles a los impulsos del viento recio; admirose el que cantaba la missa, i se asombraron las que la oían, de un caso no tan esperado, i tan manifiesto los movimientos eran admirables porque unos eran de oriente a poniente, otros de norte a sur formando otra cruz con ellos, tan flexible al parecer como si fueran de mimbres, i esto duró por largo tiempo. (Castro 1711: 23)

Otros relatos como el siguiente, que es interpretado ya desde el carisma del Colegio, se encaminan, no tanto a simbolizar la evangelización de Querétaro, sino a la de los indios gentiles de otras regiones de la Nueva España; es decir, con esto, la Cruz pasa de ser un símbolo más o menos doméstico a uno más universal. En este caso es muy clara la alusión a la evangelización del norte de la Nueva España y, establece como un claro mensaje para los religiosos, el martirio como una posibilidad real en el desempeño de su apostolado:

En el año de 1580 fueron los movimientos tan recios i tan repetidos, que puso a todo el lugar en gran cuidado; unos discurrían melancólicos, que significaban alguna fatalidad; otros esperaban algún suceso feliz, i en verdad todos lo aceptaron, porque observando el tiempo de los temblores fue en ocasiones que se levantaron los indios de el Nuevo México sacudiendo o lingo de la fe, i por este lado fue lamentable infelicidad; la felicidad fue para veinte i un religiosos ministros, que muriendo a manos de aquellos bárbaros a quienes instruían en la ley de Dios, predicándoles y llevando con religiosa paciencia los tormentos, debemos juzgar que tuvieron una muerte preciosa, que es el negocio de los negocios, de felicidad de las felicidades, pasando de la acerbidad de los dolores al dichosísimo puerto de los consuelos . (Castro 1711: 14)

De este fragmento se pueden hacer varias lecturas: una de ellas sería dentro del marco histórico, pues encontramos la referencia de que en el año de 1580 un grupo de franciscanos murieron en Nuevo México en su labor de predicar el mensaje cristiano. Otra sería el milagroso acontecimiento de que una cruz de piedra se mueva en varias direcciones, fuera de una explica- 
ción lógica y física; una más es el sentido cristiano de la muerte por la defensa de la fe, "muerte preciosa", "negocio de negocios" o "felicidad de felicidades" es decir, el martirio, "dichosísimo puerto de los consuelos".

Además de estos elementos, el cronista interpela al lector, por si acaso los argumentos de fe no lo convencen, para que reconozca la historia de la Cruz prodigiosa, a través de los comentarios de un famoso personaje de ciencia como don Carlos de Sigüenza y Góngora.

Si el testimonio que da de su crecimiento el reverendo padre provincial, i corista pareciere algún escrupuloso menos firme por ser de casa i estar la Santa Cruz en el convento de nuestra religión, puede leer el que da don Carlos de Sigüenza, catedrático de matemáticas en la Universidad de México, en el libro que intituló Las Glorias de Querétaro, i a folio 28 dice, hablando de este punto, el portento natural de estremecerse el prodigio admirabilíssimo de crecer, sientode piedra, etc... (Castro 1711: 18)

Después de presentarnos la conmoción interna, simbolizada en los temblores de la Cruz Castro describe los prodigios del crecimiento de la misma, que representa, precisamente, el aumentoen el número de cristianizados:

¿Cómo crece esta reliquia santa? No lo sabemos, las otras piedras ia nos enseñan los philosofos que crecen periurtapositionem, esto es, conviertiendo en piedra la tierra, o materia vecina, pero la Cruz no puede crecer así, principalmente lo que está en el altar fuera de la tierra, pues allí no hay materia alguna que se pueda convertir en piedra; el que da a todas las cosas el crecimiento, dijo San Pablo, es el Omnipotente Señor, el mesmo que le dio el crecer sabe el modo que se lo da. A nosotros nos toca ver lo que Dios quiere que veamos y venerar lo que permite que ignoremos. Dándole rendidas gracias a Su Majestad Soberana tanto por lo que nos oculte por lo que nos manifiesta. (Castro 1711: 20)

El siguiente cronista, fray José Díez, contribuye de manera menos abundante a la simbolización del espacio de la Cruz, sin embargo su tono será más refinado y distinguido gracias al lenguaje figurado y metafórico que lo caracteriza:

No se limitó la milagrosa virtud de la Cruz Santíssima a aquella original sola digna de recivir y sostener en sus braços al precio de nuestro resscate, y árbol dichosissimo del fruto más regalado, que quitó las amarguras de aquella fruta primera en el Paraíso de esta Nueva España (puede sin hipérbole, no agravio de otras, dar este nombre a la ameníssima Ciudad de Querétaro; no sólo por los xardines, y huertas, que la hermosean, si y más, por las místicas plantas de almas, que en exhalando olorosos aromas de virtudes son dulce recreo del celestial esposo) puso Dios un árbol de la vida, en quien se halla el fruto milagroso, para remedio de los dolientes, y para alivio, y socorro de los necessitados. Son tantos los milagros que ha obrado la Magestad inmensa por medio de esta Santíssima Cruz. (Díez 1700: 10)

También incorpora sencillas narraciones sobre los milagros de la santa Cruz; por lo general presentan una estructura simple compuesta por seis elementos: inician con la información 
de un personaje que ve cortada su cotidianidad por una enfermedad, accidente o calamidad; el segundo componente se centra en el despertar para remediar tal situación, el tercero en la invocación con oraciones y rezos a la Cruz, que puede presentarse también de forma física, a través de un piadoso contacto, es decir: tocar la Cruz, hacer cataplasmas con su polvo, etc. El cuarto consiste en la solución milagrosa, o sea la intromisión de Dios en la Historia; el quinto es el reconocimiento del atribulado devoto y el sexto la difusión gozosa del acontecimiento y su reconocimiento social.

Otro elemento distintivo en el cronista es la particularización del milagro al privilegiar aquellos relatos de los habitantes de la ciudad de Querétaro y su comarca

viendo los queretanenses las conocidas utilidades, que les seguían, con tener en su tierra mina de tan preciosos metales, para que más se enriquecieran las almas. (Díez 1700: 8)

Además, cuando relata los milagros procura que el lector se identifique con el texto por medio de un lenguaje exacerbado e hiperbólico:

Creció tanto la veneración, devoción y fee que tenían en esta Reliquia, que era y es, orgullo en las necesidades acudiendo en los mayores aprietos, a el amparo de la Santíssima Cruz de Querétaro, por ver tan bien logradas sus experiencias. Adoleció de mortal achaque, una niña llamada María, hija de Inés López, vecina de Querétaro, y después de haverla aplicado muchas medicinas, sin provecho, murió. Afligida la Madre por la pérdida de prenda que tanto amaba, invocaba el socorro de la Santíssima Cruz, con la esperança de conseguir alivio en su pena con la nueva vida de su querida hija. Impelida de interior impulso, tomando en sus brazos el hierto y helado cadáver, se fue a la hermita de la Santíssima Cruz y poniendo sobre su peana la pidió la vida de aquella a quien llorosa miraba difunta; luego que se vio en el regazo de su mexor Madre, de aquella que nos vivificó por la virtud del que en ella dio la vida, resucitó de la muerte, con indecible consuelo de piadosa Madre, quedando por testigo irrefragable de milagro tan estupendo, la mortaxa de la niña en la misma hermita; y después que se fabricó la iglesia, estuvo muchos años en ella colgada. (Díez 1700: 7)

Por su parte el cronista fray Isidro Félix de Espinosa contribuyó de manera más abundante en la simbolización del espacio mediante la disposición estructural de la obra y un discurso donde alterna el lenguaje directo, típicamente historiográfico y el figurado, que ahora identificamos más con el literario, sin mostrar timidez en el uso de metáforas, alegorías, hipérboles y otros recursos retóricos que contribuyen a conformar una obra profusa, en concordancia con los gustos de la época.

El primer libro de la Crónica Apostólica y Seráfica de todos los Colegios de Propaganda Fide de esta Nueva España hace un breve recuento de la historia prehispánica de los habitantes de la región de Querétaro para centrar su atención en la fundación del pueblo en el contexto de la conquista de los territorios ubicados al norte de ciudad de México. Espinosa le da gran relevancia a la fundación, no tanto para exaltar a la población sino para destacar el hecho providencial de que en esta población se desarrollaría el culto a la Cruz y se fundaría el primer colegio de misioneros de Propaganda Fide; es decir, la importancia de Querétaro no radica en su historia, como sería la característica visión criollista, sino en el hecho de que su fundación es provi- 
dencial por alojar al primer colegio de este tipo en América. Curiosamente esta narración del cronista marcó el relato legendario de la fundación de Querétaro y que ya forma parte de la identidad popular.

Al igual que fray José de Castro alterna la forma historiográfica y la figurada; pueden aparecer primero una y a continuación la otra; también puede ser que una prepare a la otra para intensificar el sentido:

Instaba ya el día del Apóstol Santiago en que se avían de avanzar a la población de Querétaro, y á las quatro de la mañana hizo leva el Esquadrón del Católico Adalid, y al salir del Sol se puso a la vista del Montesillo donde estaba el trozo de Gentiles, que es puntualmente en la Loma donde se plantó después la Cruz de Piedra... Resonaban entretanto las cajas, y clarines, y disparaban los que quedaron á la vista a carga cerrada los fusiles à lo alto, pues sin armas se había pactado el conflicto; y con la polvareda que levantaban los pies, y las voces que resonaban al aire, a que se juntaba el humo de la pólvora, y las flechas disparadas al viento, se obscureció el día con tal opacidad, que congojaba los ánimos de unos, y otros combatientes (pudo causar esta melancólica luz algún eclipse) y en ese mismo conflicto sirvió de Iris de paz la portentosa señal, que apareció en el Cielo..." (Espinosa 1746: 4)

En la medida que avanza esta pequeña descripción del inicio de una batalla simulada los datos objetivos disminuyen a favor de sentidos "la polvareda que levantaban los pies", "las voces que resonaban al aire" "se obscureció el día con tal opacidad" y de ahí pasa a las emociones: "tal opacidad, que congojaba los ánimos de unos, y otros combatientes", "melancólica luz" o "Iris de paz". El cronista cierra el capítulo con este párrafo y deja al lector sensibilizado para la alegoría:

Quiso el Cielo prevenir el Trono de esta Cruz Milagrosa, quando en medio de la densa obscuridad que observaron [un eclipse], no sólo los que venían de conquistadores, sino los mismos Gentiles, al tiempo de la refriega, que dejamos escrita, vieron todos una claridad tan activa, que le robó las atenciones y en el centro una Cruz refulgente, como de cuatro varas, entreblanca y roja, suspensa en el aire, y a su lado una imagen que les representaba el Patrón de las Españas Señor Santiago, casi perpendicularmente sobre el cetro donde se colocó después la Cruz de Piedra.

Con este Prodigio cesó la porfiada refriega, y causó en todos aquella reverente admiración, que haciéndolos verter muchas lágrimas produjo los deseados efectos de pacificarse los Gentiles, y admitir gustosos la luz del Santo Evangelio, que se les propuso luego que se congregaron en la planicie de este puesto. (Espinosa 1746: 4)

Como se puede observar en el texto, la disposición general del relato se agrupa en torno a dos ejes: el primero tiene que ver con la obscuridad y la lucha entre españoles e indios gentiles; el segundo con la claridad, la luz refulgente, la Cruz y el apóstol Santiago. Por otra parte, las acciones de los personajes van dela observación de la densa obscuridad mientras peleaban, a la contemplación del fenómeno de la "claridad activa". Posteriormente se presenta la aparición milagrosa de la Cruz y de Santiago apóstol, luego la admiración y conmoción de los que han observado el fenómeno y, finalmente, la aceptación gustosa de los "gentiles" para ser cristianizados. 
El relato parece una representación pictórica de claroscuros que juega con la luz y la oscuridad, lo que le da a la narración una atmósfera dramática que propicia la contemplación de los sucesos: los involucrados en la escena dejan de mirar lo que es lo "normal" y pasan a percibir la densa oscuridad, después cambian su foco de atención. Pasan de la densa oscuridad, en donde no se puede mirar nada, a la claridad activa para descubrir que en el punto central está la Cruz y junto a ella, desplazándose a un lugar más alejado de la intensidad lumínica, el apóstol Santiago.

Si se viese este pasaje desde un nivel simbólico y profundo podríamos entenderlo como una interpretación de la conquista de Querétaro: la aparición de la Cruz se presenta como una suerte de Nueva Alianza (de Dios con el pueblo), el eclipse referido al final del capítulo simboliza el paso de la oscuridad a la luz por medio de la Cruz, es decir de la condición de paganismo al de cristianismo. Por otra parte se puede ver el señalamiento de la participación franciscana en la evangelización; representada precisamente por la cruz plantada por los frailes menores en el cerro del Sangremal, el lugar donde se registraron los prodigios de la Cruz y donde se asentaría el Colegio.

Dentro de este pasaje podemos encontrar que la voz del narrador anuncia y presenta su interpretación antes de iniciar el relato, utilizando una prolepsis que intensifica el sentido de tradición -la evangelización de Querétaro por los franciscanos- y el establecimiento del Colegio, lugar desde donde se hace la relectura de la historia, para después darnos su conclusión sobre el providencial hecho con las palabras del inicio "Quiso el Cielo prevenir el Trono de la Cruz Milagrosa”. También es importante señalar en este cuadro alegórico el sentido hiperbólico y la adjetivación que le da un sentido maravilloso y sobrenatural.

$\mathrm{Al}$ igual que los dos cronistas anteriores va a presentar pequeños relatos sobre los prodigios de la Cruz, los ejemplos son más variados y abundantes pues incorpora casos que ocurren a personajes de distintas castas: primero con indios, luego españoles y otras castas. Tiene el cuidado de poner también a personajes de distintos oficios, fortunas y estamentos:

Para renovar todos los años su devoto obsequio la Nobleza de Querétaro, marchaba día Invención de la Santa Cruz, con una muy lucida, y costosa Infantería, antes del año de mil seiscientos y cincuenta: y al entrar en la Iglesia de esta Santa Cruz, cuando el Alférez tremolaba la Vandeta, y la rendía a lo que lo es del Rey Supremo, hizo la Cruz, a vista de todos, una inclinación de cabeza, que casi bajó hasta la tierra, como admitiendo aquel reverente obsequio. Tal sería la Fe, y devoción de aquel Congresso, que mereció la aprobasse el Cielo con tan raro prodigio. (Espinosa: 1746: 15)

Aquí destacan dos elementos: el primero conformado por el ritual protocolario de saludo a la Cruz con inclinación de cabeza y reverencia con las insignias y banderín que enfatizan la jerarquía y distinción social; el segundo aspecto que se desprende de éste es el de la aprobación y renovación de los vínculos comunitarios en el lugar de la Cruz.

Como si no fuese suficiente presenta también los favores que la Santa Cruz regala al clero, sea éste secular o regular:

Muy Singular y, misterioso sucesso experimentó un Secular devoto, que atraído de la fama que por todas partes se difundía de los milagros de esta Cruz Santíssima, vino de fuera a visitarla. 
Estando solo en la antigua Hermita, quando la Cruz no estaba guarnecida con vidrieras, llegó con reverente culto a tocar el Rosario para llevarlo como prenda de que avía logrado el contacto de tan Santa Reliquia. Como si la Piedra fuera Imán, prendió el Rosario con tal fuerza, que no le bastaron diligencias humanas para despegarlo. (Espinosa 1746: 46)

A través de cuatro capítulos el cronista da cuenta de los prodigios de la Santa Cruz en experiencias concretas de varios personajes, sin embargo para cerrar el tema presenta dos últimos relatos que constatan los favores recibidos por la Cruz; estos personajes son fray José de Castro y el cronista Espinosa:

Tanta fee tenía de los polvos de la Cruz el Reverendo Padre Fray Joseph de Castro, Varón memorable de este Colegio que en viéndose aquejado de algún achaque, apelaba a esta soberana medicina; y sentía luego el remedio Quizá el Señor permite, que esta Cruz crezca (dejó escrito dicho Padre) para no faltasse a los devotos esta suave, y olorosa medicina. Cierro este capítulo, protestando no califico milagro, lo que el año pasado por el mes de Enero de quarenta vieron todos los de esta comunidad Santa a favor de mi salud ejecutado, por la invocación a la Cruz Santíssima. Estando ya Sacramentado, y cansada de remedios la medicina por un dolor cardiálgico, que duró más de ocho horas, no hallando menor alivio, clamé de corazón a la Cruz, haciendo de sus maravillas recuerdo: en este mismo tiempo entró el Enfermero con una pella, que encontró por acaso, y sin orden del Médico, que estaba pared de por medio, calentola con los conocimientosque antes avían aplicado, y la primera buelta, que dio sobre el estómago, cessaron el dolor, la congoja, y otros accidentes que me tuvieron cercano al último conflicto. No pude menos que persuadirme ser favor especial de esta milagrosíssima Cruz. (Espinosa 1746: 28)

La estructura de la Crónica de fray Isidro Félix de Espinosa contribuye a la formación de la simbolización de la Cruz y el espacio conventual que la cobija, tanto en el texto como en la realidad. El tema del origen y desarrollo del culto de la Cruz se despliega a lo largo de dieciséis capítulos del primer libro; los primeros los dedica a la fundación de Querétaro, después se ocupa de relatar el origen de la Cruz y los prodigios que ocurren, finalmente se dedica a narrar cómo la pobre y sencilla ermita de los tiempos de la fundación de Querétaro se transforma en un pequeño templo con un cuarto anexo. Posteriormente se detiene para contar las adversidades y vicisitudes que tuvieron que pasar los religiosos y feligreses para la ampliación del templo y la construcción de un pequeño claustro ante la oposición de las autoridades virreinales. Esta parte de la crónica es muy importante porque la lucha por la dignificación del espacio es en realidad un reflejo del combate entre el bien y el mal, de manera que se resuelve este drama cuando las autoridades sucumben ante el poder de la Cruz. La oposición se resuelve, la construcción de los edificios se lleva a cabo y los usos del lugar se coronan con la instauración del primer colegio de Propaganda Fide de la Nueva España.

Fray Juan Domingo Arricivita ya no abordó el tema de la simbolización de la Cruz en su crónica debido a que por ser una obra tardía, realizada en el último cuarto del siglo XVIII y publicada en 1792, los gustos literarios se encaminaban a las formas ilustradas; así, el cronista prefiere formas historiográficas más directas, que privilegian la idea de objetividad; menos figurativas, reduce el número de metáforas y las usa para intensificar el discurso en los puntos 
temáticos que considera más importantes o para asignarles una función edificante. También porque considera que los cronistas anteriores ya se habían ocupado del asunto y, por último, por estar concebido como la continuación de la obra de fray Isidro Félix de Espinosa.

\section{Referencias bibliográficas}

Alonso de Diego, M. (2003). Retórica, predicación y vida cotidiana en la ciudad de México (1735) según Francisco de la Concepción Barbosa, OFM. Anuario de Historia de la Iglesia, XII, 387-393.

Arlegui, J. (1737). Chrónica de la Provincia de Nuestro Padre San Francisco de Zacatecas. México: Imprenta de Bernardo de Hogal.

Arricivita, J. (1792). Crónica Seráfica y Apostólica del Colegio de Propaganda Fide de la Santa Cruz de Querétaro en la Nueva España. México: Imprenta de Felipe de Zúñiga y Ontiveros.

Beristáin de Souza, J. M. (1980 [1816]). Biblioteca Hispanoamericana Septentrional. México: UNAM.

Brading, David A. (1991). Orbe Indiano. De la monarquía católica a la república criolla 1492-1867. México: Fondo de Cultura Económica.

Bringas de Mazaneda y Encinas, D. (1960). Crónica Apostólica y Seráfica del Colegio de Propaganda Fide de la Santa Cruz de Querétaro. Querétaro: Ediciones Cimatario.

Castro, J. de. (1711). Primera Parte de la Crónica de Propaganda Fide en la Nueva España. Ms. Archivo de la Curia General de la Orden de Frailes Menores en Roma.

Cohen, J. (1982). La significación poética. El lenguaje de la poesía. Teoría de la poeticidad. Madrid: Gredos.

Correa Etchegaray, L., Herrera Rubén, L., \& otros. (2006). La construcción retórica de la realidad. La Compañía de Jesús. México: Universidad Iberoamericana.

Díez J. (1700). Apostólicos empleos de los Hijos del Seraphin llagado, obreros evangélicos, del Colegio de la Santíssima Cruz de la ciudad de Santiago de Querétaro. Roma: Ms. Archivo de la Curia General de la Orden de Frailes Menores.

Dorra, R. (2002). La retórica como arte de la mirada. México: Plaza y Valdés.

Dosse, F. (2007). El arte de la biografía. México: Universidad Iberoamericana.

Eliade, M. (2010). Mitos, sueños y misterios. Barcelona: Kairós.

Espinosa, I. F. de. (1746). Crónica Apostólica y Seráfica de todos los colegios de Propaganda Fide de esta Nueva España de Missioneros Franciscanos Observantes: erigidos con autoridad pontificia, y regia, para la reformación de los fieles, y conversión de los gentiles. México: impreso por la Viuda de Joseph Bernardo del Hogal.

(2003). Crónica Franciscana de Michoacán: apuntamientos bibliográficos de Nicolás León. Morelia: Instituto de Investigaciones Históricas de la Universidad Michoacana de San Nicolás de Hidalgo / Morevallado Editores.

. (1737). El Peregrino septentrional Atlante delineado en la exemplaríssima vida del Venerable Padre Fray Antonio Margil de Jesús. México: Joseph Bernardo de Hogal.

- (1747). Nuevas empresas del Peregrino Americano Septentrional Atlante, Descubiertas en lo que hizo cuando vivía, y aún después de su muerte ha manifestado el Venerable Padre Fray Antonio Margil de Jesús. De nuevo averiguados, que no están en la Vida de este Siervo de Dios estampada en el año de 1737 y pueden dessear los afectos de este Varón memorable. México: Imprenta Real del Superio Gobierno, y del Nuevo Rezado, de Doña María de Rivera, en el Empedradillo. 
Filinich, M. I. (2003). Descripción. Buenos Aires: Eudeba.

García Ponce, J. (1968). El arte y lo sagrado. In La aparición de lo invisible. México: Siglo XXI Editores.

Gómez Canedo, L. (1993). Conquista, evangelización y promoción social. Ensayos y estudios críticos sobre la contribución franciscana a los orígenes cristianos de México (Siglos XVI-XVIII). México: Porrúa.

-. (1964). Estudio introductorio. In I. Félix de Espinosa, Crónica de todos los colegios de Propaganda Fide de esta Nueva España. Washington, Academy of American Franciscan History.

Marchese, A.; \& Forradellas, J. (2005). Diccionario de retórica, crítica y terminología literaria. Barcelona: Ariel.

Mardones, J. Mª (2003). La vida del símbolo. La dimensión simbólica de la religión. Santander: Sal Terra.

Medina, J. T. (1989). La imprenta en México (1539-1821). Tomo V. 1745-1767. México: UNAM.

Mendieta, G. de. (1997). Historia Eccleiástica Indiana. México: Conaculta.

Navarrete, F. A. (1739). Relación Peregrina de el agua Corriente, que para beber, y vivir goza la Muy Noble, Leal, y Florida Ciudad de Santiago de Querétaro. México: Impresa por Bernardo de Hogal.

Rea, A. de la. (1996). Crónica de la Orden de Nuestro Seráfico Padre San Francisco. Provincia de San Pedro y San Pablo de Michoacán en la Nueva España. Patricia Escandón (Ed.). Zamora: El Colegio de Michoacán / Fideicomiso Teixidor.

Rodríguez Domínguez, G. (2016). Viaje de América a Roma, de José de Castro. G. Rodríguez Domínguez (Ed.). Xalapa: Universidad Veracruzana.

. (2010). José Castro, escritor mexicano del siglo XVII, edición y estudio de su obra poética. Tesis doctoral. Universidad de Salamanca.

Rubial García, A. (2001). La santidad controvertida. México: Fondo de Cultura Económica.

. (1998). Las generaciones preilustradas novohispanas y la literatura compendiosa en la época de Sor Juana. In C. B. López Portillo (Coord.), Sor Juana y su mundo: una mirada actual. Memorias del congreso internacional, México: Claustro de Sor Juana/UNESCO/Fondo de Cultura Económica.

Santa Gertrudis, F. X. de. (1722). Cruz de piedra, imán de la devoción, venerada en el Colegio de Missioneros Apostólicos de la Ciudad de Santiago de Querétaro. México: Juan Francisco de Ortega y Bonilla.

Sigüenza y Góngora, C. (1965 [1680]). Glorias de Querétaro. En la nueva Congregación Eclesiástica de María Santísima de Guadalupe. Querétaro: Gobierno del Estado de Querétaro.

Torquemada, J. de. (1986 [1723]). Veintiun libros rituales y Monarquía Indiana. México: Porrúa.

Vogeley, N.; Ramos Medina, M.; et alli. (2011). Historia de la Literatura Mexicana desde sus orígenes hasta nuestyros días. Vol. 3 Cambios de reglas, mentalidades y recursos retóricos en la Nueva España del siglo XVIII. México: UNAM/ Siglo XXI Editores. 
